\title{
Ruthenium-BINAP Catalyzed Alcohol C-H tert-Prenylation via 1,3-Enyne Transfer Hydrogenation: Beyond Stoichiometric Carbanions in Enantioselective Carbonyl Propargylation
}

\author{
Khoa D. Nguyen ${ }^{\dagger}$, Daniel Herkommer ${ }^{\dagger}$, and Michael J. Krische* \\ University of Texas at Austin, Department of Chemistry, Austin, TX 78712, USA
}

\begin{abstract}
The chiral ruthenium complex formed in situ from $(\mathrm{TFA})_{2} \mathrm{Ru}(\mathrm{CO})\left(\mathrm{PPh}_{3}\right)_{2}$ and $(R)$-BINAP is found to catalyze the enantioselective $\mathrm{C}-\mathrm{C}$ coupling of diverse primary alcohols with the 1,3enyne, TMSC $\equiv \mathrm{CC}(\mathrm{Me})=\mathrm{CH}_{2}$, to form secondary homopropargyl alcohols bearing gem-dimethyl groups. All reagents for this byproduct-free coupling are inexpensive and commercially available, making this protocol a practical alternative to stoichiometric carbanions in enantioselective carbonyl reverse prenylation.
\end{abstract}

\section{Graphical Abstract}

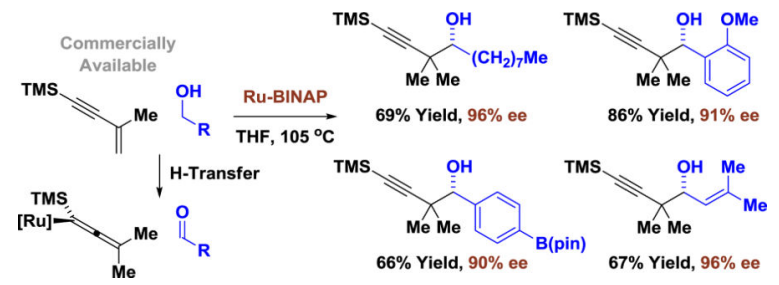

\begin{abstract}
By merging the characteristics of carbonyl addition and transfer hydrogenation, we have developed a broad, new class of catalytic C-C couplings that directly convert lower alcohols to higher alcohols by way of transient carbonyl-organometal pairs. ${ }^{1 \mathrm{a}}$ This suite of catalytic methods encompasses transformations relevant to polyketide construction, ${ }^{1 \mathrm{~b}}$ for example, enantioselective alcohol C-H allylation ${ }^{2}$ and crotylation. ${ }^{3,4,5}$ Neopentyl alcohols bearing gem-dimethyl groups are found in numerous polyketide natural products, ${ }^{6 \mathrm{a}}$ and are ubiquitous among terpenoid natural products (Figure 1). ${ }^{6 \mathrm{~b}, \mathrm{c}}$ Preparation of these structural motifs in enantiomerically enriched form has been accomplished through the addition of prenylmetal reagents to carbonyl compounds. ${ }^{7-10}$ The reductive coupling of carbonyl compounds with prenyl halides or 1,1-dimethyl allene - the very precursors from which the aforementioned prenylmetal reagents are derived - would further streamline the synthesis of
\end{abstract}

\footnotetext{
Corresponding Author. mkrische@mail.utexas.edu.

$†$ These authors contributed equally to this work.

Supporting Information Available: Experimental procedures and spectral data. HPLC traces corresponding to racemic and enantiomerically enriched samples. Single crystal X-ray diffraction data for compounds $\mathbf{3 d}$ and $\mathbf{3 m}$. This material is available free of charge via the internet at http://pubs.acs.org.

The authors declare no competing financial interest.
} 
such neopentyl alcohols. ${ }^{11-13}$ While racemic variants exist, ${ }^{11-13}$ catalytic asymmetric couplings of this type were unknown until our report on the enantioselective coupling of primary alcohols with 1,1-dimethyl allene via iridium catalyzed transfer hydrogenation. ${ }^{14}$ Enantioselective carbonyl propargylations that generate gem-dimethyl bearing homopropargyl neopentyl alcohols have not been described. ${ }^{15}$ Here, using an inexpensive chiral ruthenium complex formed in situ from (TFA $)_{2} \mathrm{Ru}(\mathrm{CO})\left(\mathrm{PPh}_{3}\right)_{2}$ and $(R)$-BINAP, ${ }^{16}$ we report the first catalytic enantioselective carbonyl tert-prenylation via propargylation. ${ }^{17,18}$

In 2008, initial studies on ruthenium catalyzed propargylation mediated by 1,3-enynes were undertaken. ${ }^{17}$ Despite years of investigation, highly enantioselective variants were elusive. For these reactions, which employ 1,3-enynes with unsubstituted vinyl moieties $\left(\mathrm{RC} \equiv \mathrm{CCH}=\mathrm{CH}_{2}\right)$, the stereochemical fidelity of two events ultimately determines enantioselectivity: (a) hydrometalation of the 1,3-enyne to form an axially chiral allenylruthenium intermediate, and (b) carbonyl addition to form the secondary homopropargyl alcohol. For the commercially available 1,3-enyne 1a, TMSC $\equiv \mathrm{CC}(\mathrm{Me})=\mathrm{CH}_{2}$, hydrometalation is no longer enantiodetermining and carbonyl addition would occur by way of a more crowded transition structure. It was reasoned these features would simplify the optimization of enantioselectivity. In the event, 1,3-enyne 1a was exposed to $p$-bromobenzyl alcohol $\mathbf{2 b}$ in the presence of the ruthenium catalyst generated in situ from $\mathrm{HCIRu}(\mathrm{CO})\left(\mathrm{PPh}_{3}\right)_{3}$ and $(R)$-BINAP in THF $(0.5 \mathrm{M})$ at $105{ }^{\circ} \mathrm{C}$. The desired gem-dimethyl bearing homopropargyl neopentyl alcohol $\mathbf{3 b}$ was formed in $72 \%$ isolated yield and $80 \%$ ee (Scheme 1). In the absence of $(R)$-BINAP under otherwise identical conditions, a racemic background reaction was identified, which might compromise the level of asymmetric induction. Using commercially available $(\mathrm{TFA})_{2} \mathrm{Ru}(\mathrm{CO})\left(\mathrm{PPh}_{3}\right)_{2}\left(\mathrm{TFA}=\mathrm{F}_{3} \mathrm{CCO}_{2}\right)$ as precatalyst, a background reaction was not evident and the adduct $\mathbf{3 b}$ could be obtained in $75 \%$ yield and $94 \%$ enantiomeric excess. These key optimization experiments represent only a small fraction of those performed. Further variation of the reaction parameters, including ligand, ruthenium precatalyst, temperature, solvent and reactant stoichiometry did not enhance conversion or selectivity. Attempted couplings using 1,3-enynes substituted by alternate trialkylsilyl groups $\left(\mathrm{Ph}_{2}{ }^{t} \mathrm{BuSi}, \mathrm{Me}_{2} \mathrm{PhSi},{ }^{i} \mathrm{Pr}_{3} \mathrm{Si}\right)$ resulted in low conversion (Scheme 1).

To assess the scope of this process, our optimal conditions were applied to the coupling of 1,3-enyne 1a with primary alcohols $\mathbf{2 a}-\mathbf{2 r}$ (Table 1). Benzylic alcohols $\mathbf{2 a}-\mathbf{2 l}$ were converted to adducts 3a-3l, respectively, in moderate to excellent isolated yields and uniformly high levels of enantioselectivity. A range of functional groups and substitution patters are tolerated. However, electron deficient benzylic alcohols, for example, $p-\mathrm{CF}_{3}$ substitued benzyl alcohol 2l, were less efficient partners for coupling, which may be due to a higher energetic barrier for dehydrogenation. Allylic alcohols $\mathbf{2 m - 2 o}$ were converted to 1,5enynes 3m-3o, respectively, in good yield with high enantioselectivities. Aliphatic alcohols $\mathbf{2 p - 2 r}$ were converted to the homopropargyl neopentyl alcohols $\mathbf{3 p}-\mathbf{3 r}$, respectively, in good yield with consistently high enantioselectivity. Absolute stereochemistry was determined by single crystal X-ray diffraction analysis of compounds $\mathbf{3 d}$ and $\mathbf{3 m}$. The stereochemistry of all other adducts was assigned in analogy. The chiral $\beta$-stereogenic alcohol citronellol $2 \mathrm{~s}$ undergoes coupling with complete levels of catalyst directed diastereoselectivity using the 
ruthenium catalyst modified by either $(R)$-or $(S)$-BINAP (eq. 1 and 2, respectively). Finally, beyond redoxneutral couplings of alcohols, 2-propanol mediated reductive coupling from the aldehyde oxidation level is possible, as illustrated in the conversion of dehydro-2a and dehydro-2r to homopropargyl alcohols $\mathbf{3 a}$ and $\mathbf{3 r}$, respectively (eq. 3).

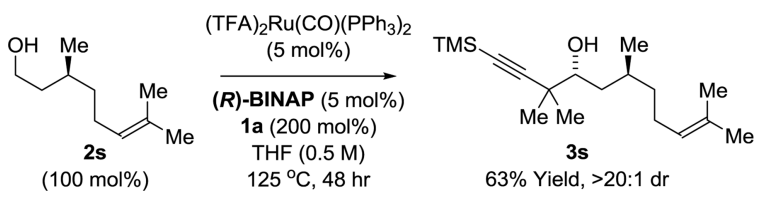

(eq. 1)

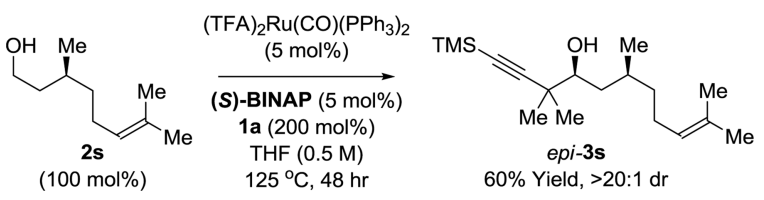

(eq. 2)

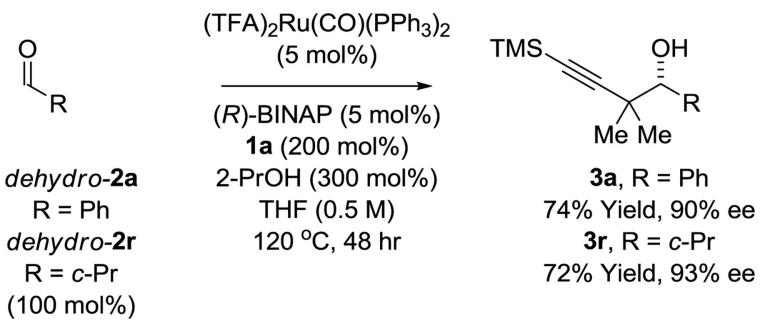

(eq. 3)

A catalytic mechanism has been proposed, as illustrated in the coupling of enyne 1a with benzyl alcohol 2a (Scheme 2). Substitution of trifluoroacetate with benzyl alcohol 2a provides the ruthenium alkoxide $\mathbf{I}$, which undergoes $\beta$-hydride elimination to furnish the aldehyde dehydro-2a and the ruthenium hydride $\mathbf{I I} .{ }^{19}$ Enyne hydrometalation delivers the tertiary $\sigma$-propargyl complex III, which isomerizes to the thermodynamically favored $\sigma$ allenyl complex IV. The stoichiometric reaction of $\mathrm{HClRu}(\mathrm{CO})\left(\mathrm{PPh}_{3}\right)_{3}$ with conjugated enynes to form $\sigma$-allenyl complexes characterized by single crystal X-ray diffraction has been reported. ${ }^{20}$ Coordination of the aldehyde as in complex $\mathbf{V}$ precedes carbonyl addition to form the homopropargylic ruthenium alkoxide VI. At this stage, release of the homopropargyl alcohol 3a may occur with the assistance of trifluoroacetic acid or through direct exchange with benzyl alcohol $\mathbf{2 a}$.

The veracity of our interpretation of the catalytic mechanism was challenged through two deuterium labeling experiments (Scheme 2). In both experiments, adventitious water may contribute to the loss of deuterium. ${ }^{21}$ Ruthenium catalyzed C-C coupling of 1,3-enyne 1a with deuterio-2b under standard conditions delivered deuterio-3b in $67 \%$ yield. Deuterium is 
largely retained at the carbinol position $\left(\mathrm{H}_{\mathrm{c}}=87 \%{ }^{2} \mathrm{H}\right)$, suggesting there is little reversibility in the hydrogen transfer between enyne 1a and primary alcohol deuterio-2 $\mathbf{b}$ and that the homopropargylic alcohol product is resistant to dehydrogenation, which would erode enantioselectivity. Deuterium is incorporated at the diastereotopic methyl groups $\left(\mathrm{H}_{\mathrm{a}, \mathrm{b}}=\right.$ $70 \%{ }^{2} \mathrm{H}$ ) in 3:1 ratio, ${ }^{22}$ suggesting interconversion between the $\sigma$-propargyl- and $\sigma$ allenylruthenium intermediates is slightly slower than carbonyl addition. The pattern of deuterium incorporation in the reductive coupling of 1,3-enyne 1a with dehydro-2b mediated by $d_{\delta}$-2-propanol is consistent with reversible hydrogen transfer between $d_{8}-2$ propanol, 1,3-enyne 1a and dehydro-2b in advance of carbonyl addition. In the reductive coupling, which is performed at higher temperature $\left(120^{\circ} \mathrm{C}\right)$, a $1.7: 1$ ratio of deuterium is observed at the diastereotopic methyl groups $\left(\mathrm{H}_{\mathrm{a}, \mathrm{b}}=130 \%{ }^{2} \mathrm{H}\right) .{ }^{22}$

To illustrate the utility of this methodology, adduct $\mathbf{3 b}$ was desilylated (not shown) and the resulting terminal alkyne $\mathbf{4 b}$ was subjected to a series of transformations in the absence of hydroxyl protection (eq. 4-6). Hydrozirconation of $\mathbf{4 b}$ followed by treatment with elemental iodine delivers the vinyl iodide trans-5b in good yield (eq. 4). ${ }^{23}$ Conversion of $\mathbf{4 b}$ to the corresponding acetylenic iodide ${ }^{24}$ followed by diimide reduction of the alkyne using 2nitrobenzenesulfonylhydrazide (NBSH) ${ }^{25}$ delivers the isomeric vinyl iodide cis-5b (eq. 5). Finally, exposure of $\mathbf{4 b}$ to 3-buten-2-ol in the presence of the indicated cationic Cpruthenium(II) catalyst results in formation of $\gamma, \delta$-unsaturated ketone $\mathbf{6 b}$ (eq. 6) ${ }^{26}$
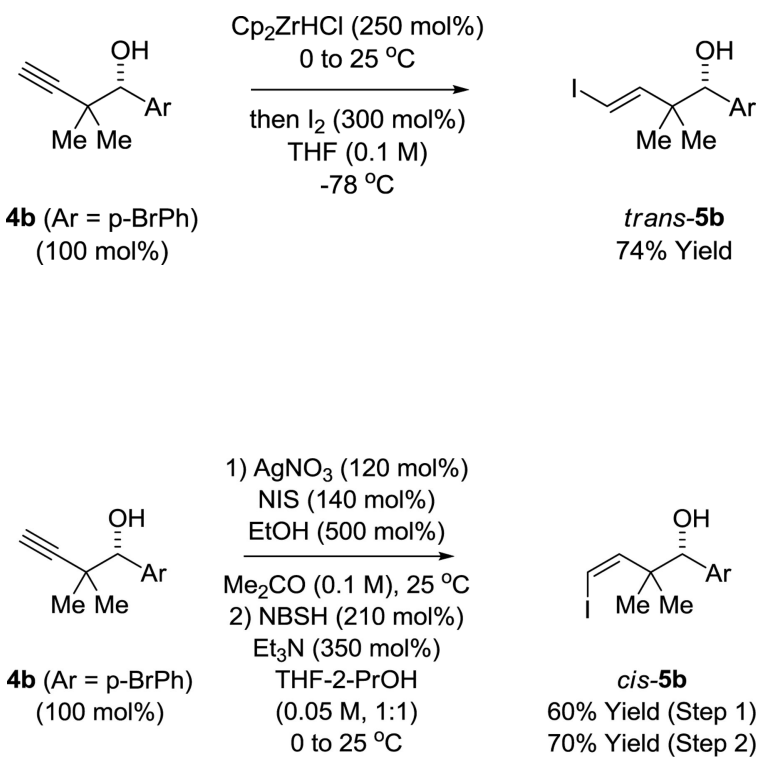

(eq. 5) 


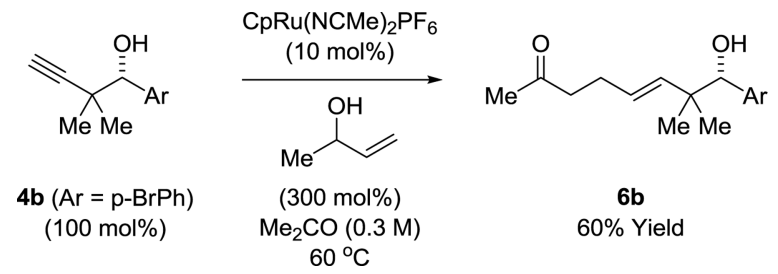

(eq. 6)

In summary, under the conditions of transfer hydrogenation using a simple rutheniumBINAP catalyst, diverse primary alcohols $\mathbf{2 a}-\mathbf{2 s}$ couple with conjugated enyne $\mathbf{1 a}$ to form secondary homopropargyl alcohols $\mathbf{3 a}-\mathbf{3 s}$ bearing gem-dimethyl groups with uniformly high levels of enantioselectivity. Further, the same catalytic conditions promote the 2-propanolmediated reductive coupling of aldehydes with enyne 1a to furnish identical products in an equally efficient and selective manner. More broadly, this work and earlier studies from our laboratory ${ }^{1}$ demonstrate that the merger of transfer hydrogenation and carbonyl addition enable a departure from stoichiometric carbanion chemistry in an ever-increasing variety of $\mathrm{C}-\mathrm{C}$ bond forming processes.

\section{Supplementary Material}

Refer to Web version on PubMed Central for supplementary material.

\section{Acknowledgments}

The Robert A. Welch Foundation (F-0038), the NIH-NIGMS (RO1-GM069445) and the Feodor Lynen postdoctoral fellowship program administered by the Alexander von Humboldt Foundation are acknowledged for partial support of this research. We thank Mr. Daniel Eppel for skillful technical assistance.

\section{REFERENCES}

1. Reviews: Ketcham JM, Shin I, Montgomery TP, Krische MJ. Angew. Chem. Int. Ed. 2014; 53:9142. Dechert-Schmitt A-MR, Schmitt DC, Gao X, Itoh T, Krische MJ. Nat. Prod. Rep. 2014; 31:504. [PubMed: 24514754]

2. Enantioselective alcohol C-H allylation, see: Shin I, Wang G, Krische MJ. Chem. Eur. J. 2014; 20:13382. [PubMed: 25169904] and references cited therein.

3. Enantioselective alcohol C-H crotylation (iridium): Gao X, Han H, Krische MJ. J. Am. Chem. Soc. 2011; 133:12795. [PubMed: 21739988] and references cited therein.

4. Enantioselective alcohol C-H crotylation (ruthenium): Zbieg JR, Yamaguchi E, McInturff EL, Krische MJ. Science. 2012; 336:324. [PubMed: 22442385] McInturff EL, Yamaguchi E, Krische MJ. J. Am. Chem. Soc. 2012; 134:20628. [PubMed: 23234459] and references cited therein.

5. For selected reviews on enantioselective carbonyl allylation and crotylation, see: Yamamoto Y, Asao N. Chem. Rev. 1993; 93:2207. Ramachandran PV. Aldrichim. Acta. 2002; 35:23. Kennedy JWJ, Hall DG. Angew. Chem. Int. Ed. 2003; 42:4732. Denmark SE, Fu J. Chem. Rev. 2003; 103:2763. [PubMed: 12914480] Yu C-M, Youn J, Jung H-K. Bull. Korean Chem. Soc. 2006; 27:463. Marek I, Sklute G. Chem. Commun. 2007:1683. Hall DG. Synlett. 2007:1644. Li J, Menche D. Synthesis. 2009:2293. Leighton JL. Aldrichim. Acta. 2010; 43:3. Yus M, González-Gómez JC, Foubelo F. Chem. Rev. 2011; 111:7774. [PubMed: 21923136] Pasco M, Gilboa N, Mejuch T, Marek I. Organometallics. 2013; 32:942. 
6. (a) Barton, D.; Nakanishi, K.; Meth-Cohn, O. Polyketides and Other Secondary Metabolites Including Fatty Acids and Their Derivatives. In: Sankawa, U., editor. Comprehensive Natural Products Chemistry. 1st. Vol. 1. Oxford, UK: Elsevier; 1999. (b) Glasby, JS., editor. Encyclopedia of the Terpenoids. New York: Wiley; 1982. (c) Breitmaier, E., editor. Terpenes Flavors, Fragrances, Pharmaca, Pheromones. Weinheim: Wiley-VCH; 2006.

7. For enantioselective carbonyl tert-prenylation employing allylboron reagents, see: Brown HC, Jadhav PK. Tetrahedron Lett. 1984; 25:1215. Jadhav PK, Bhat KS, Perumal T, Brown HC. J. Org. Chem. 1986; 51:432. Roush WR, Marron TG. Tetrahedron Lett. 1993; 34:5421. Alam R, Vollgraff T, Eriksson L, Szabó KJ. J. Am. Chem. Soc. 2015; 137:11262. [PubMed: 26316158]

8. For enantioselective carbonyl tert-prenylation employing allylindium reagents, see: Loh T-P, Zhou JR, Li X-R. Tetrahedron Lett. 1999; 40:9333. Loh T-P, Zhou JR, Yin Z. Org. Lett. 1999; 1:1855.

9. For enantioselective carbonyl tert-prenylation employing allylsilicon reagents, see: Nakajima M, Saito M, Shiro M, Hashimoto S-I. J. Am. Chem. Soc. 1998; 120:6419. Nakajima M, Kotani S, Ishizuka T, Hashimoto S. Tetrahedron Lett. 2005; 46:157. Denmark SE, Fu J. J. Am. Chem. Soc. 2001; 123:9488. [PubMed: 11562250] Denmark SE, Fu J, Lawler MJ. J. Org. Chem. 2006; 71:1523. [PubMed: 16468801]

10. For enantioselective carbonyl tert-prenylation employing allyltin reagents, see: Boldrini GP, Tagliavini E, Trombini C, Umani-Ronchi A. J. Chem. Soc. Chem. Commun. 1986:685. Boldrini GP, Lodi L, Tagliavini E, Tarasco C, Trombini C, Umani-Ronchi A. J. Org. Chem. 1987; 52:5447.

11. For Lewis acid catalyzed reductive coupling of prenyl bromide with carbonyl compounds mediated by zinc to form racemic products of tert-prenylation, see: Maeda H, Shono K, Ohmori H. Chem. Pharm. Bull. 1994; 42:1808. Fleury LM, Kosal AD, Masters JT, Ashfeld BL. J. Org. Chem. 2013; 78:253. [PubMed: 23094703]

12. For palladium catalyzed reductive coupling of 1,1-dimethylallene to carbonyl compounds mediated by $\mathrm{SnCl} 2$ to form racemic products of tert-prenylation, see: Chang H-M, Cheng C-H. Org. Lett. 2000; 2:3439. [PubMed: 11082003]

13. For nickel catalyzed reductive coupling of prenyl acetate with carbonyl compounds mediated by $\mathrm{B}_{2}$ (pin) $)_{2}$ to form racemic products of tert-prenylation, see: Zhang P, Roundtree IA, Morken JP. Org. Lett. 2012; 14:1416. [PubMed: 22375950]

14. Han SB, Kim IS, Han H, Krische MJ. J. Am. Chem. Soc. 2009; 131:6916. Addition/Correction: J. Am. Chem. Soc.2010, 132, 12517. [PubMed: 19453190]

15. For carbonyl tert-propargylation to form racemic gem-dimethyl bearing homopropargylic neopentyl alcohols, see: Satoh M, Nomoto Y, Miyaura N, Suzuki A. Tetrahedron Lett. 1989; 30:3789. Nakagawa T, Kasatkin A, Sato F. Tetrahedron Lett. 1995; 36:3207. Yang F, Zhao G, Ding Y. Tetrahedron Lett. 2001; 42:2839. Ito H, Sasaki Y, Sawamura M. J. Am. Chem. Soc. 2008; 130:15774. [PubMed: 18973297]

16. For the first examples of highly enantioselective ruthenium catalyzed transfer hydrogenation, see: Hashiguchi S, Fujii A, Takehara J, Ikariya T, Noyori R. J. Am. Chem. Soc. 1995; 117:7562.

17. For ruthenium catalyzed 1,3-enyne-mediated propargylations to form racemic products, see: Patman RL, Williams VM, Bower JF, Krische MJ. Angew. Chem. Int. Ed. 2008; 47:5220. Geary LM, Leung JC, Krische MJ. Chem. Eur. J. 2012; 18:16823. [PubMed: 23147989]

18. For iridium catalyzed propargylations to form enantiomerically enriched products mediated by $1,3-$ enyne or propargyl chlorides, see: Geary LM, Woo SK, Leung JC, Krische MJ. Angew. Chem. Int. Ed. 2012; 51:2972. Woo SK, Geary LM, Krische MJ. Angew. Chem. Int. Ed. 2012; 51:7830.

19. Dobson A, Robinson SD. Inorg. Chem. 1977; 16:137.

20. Wakatsuki Y, Yamazaki H, Maruyama Y, Shimizu I. J. Chem. Soc. Chem. Commun. 1991:261.

21. Tse SKS, Xue P, Lin Z, Jia G. Adv. Synth. Catal. 2010; 352:1512.

22. The diastereotopic methyl groups of deuterio-3b could not assigned.

23. Hart DW, Blackburn TF, Schwartz J. J. Am. Chem. Soc. 1974; 96:679.

24. Hofmeister H, Annen K, Laurent H, Wiechert R. Angew. Chem. Int. Ed. Engl. 1984; 23:727.

25. Myers AG, Zheng B, Movassaghi M. J. Org. Chem. 1987; 62:7507. [PubMed: 11671877]

26. Trost BM, Toste FD, Pinkerton AB. Chem. Rev. 2001; 101:2067. [PubMed: 11710241] 
Representative gem-Dimethvl Containing Polvketide, Terpenoid Natural Products

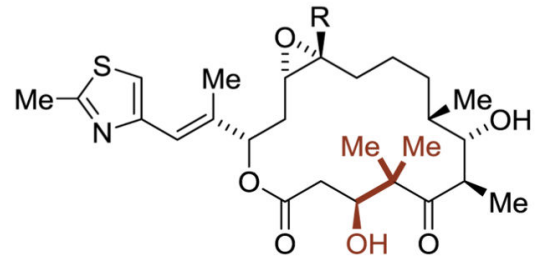

Epothilone $A(R=H)$

Epothilone $B(R=M e)$

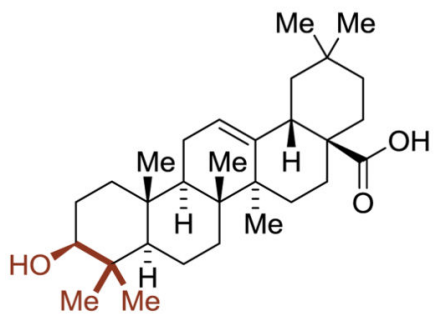

Oleanolic acid

Representative Methods for Enantioselective Carbonvl tert-Prenvlation (ref. 7-10)

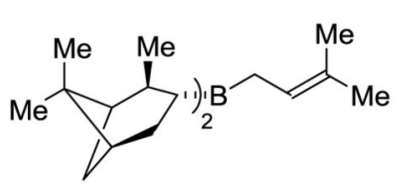

Brown

Tetrahedron Lett. 1984, 1215<smiles></smiles>

Nakajima

J. Am. Chem. Soc.

$1998,120,6419$<smiles>CCOC(=O)[C@@H]1O[C@@H](CC=C(C)C)C([NH3+])([SeH])O1</smiles>

Umani-Ronchi

J. Chem. Soc., Chem. Comm. 1986, 685

Prior Work: Iridium Catalyzed C-C Coupling of Alcohols with 1,1-Dimethylallene (ref. 14)

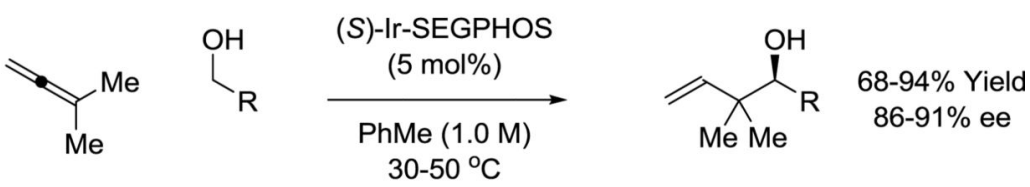

This Work: Ruthenium Catalyzed C-C Coupling of Alcohols with 1,3-enynes

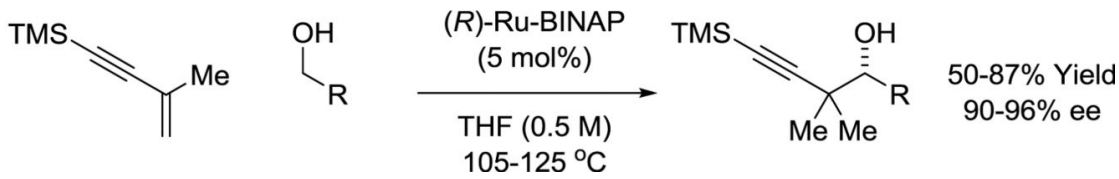

Figure 1.

Carbonyl tert-prenylation for polyketide and terpenoid construction. 
<smiles>C=C(C)C#CSC(C)(C)C</smiles>

$1 a$ (200 mol\%) (100 mol\%)

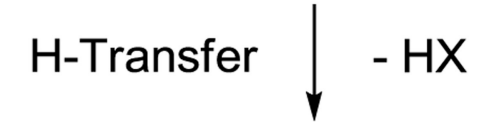

$$
\text { TMS, }
$$<smiles>[R]CO</smiles>

$2 b$
Scheme 1. further details.
RuLn (5 mol\%)

$(R)$-BINAP (5 mol\%)

THF (0.5 M)

$105^{\circ} \mathrm{C}, 24 \mathrm{hr}$

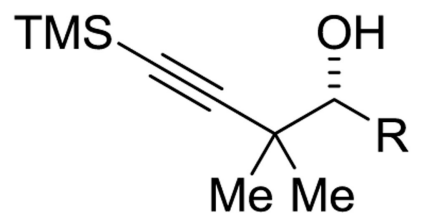

3b

$\mathrm{HClRu}(\mathrm{CO})\left(\mathrm{PPh}_{3}\right)_{3}$ Without $(R)$-BINAP $(\mathrm{TFA})_{2} \mathrm{Ru}(\mathrm{CO})\left(\mathrm{PPh}_{3}\right)_{2}$<smiles>[R]C(O[Ga]C(C)(C)C)C(C)(C)C#CC(C)C</smiles>

$72 \%$ Yield, $80 \%$ ee 9\% Yield

\section{5\% Yield, $94 \%$ ee}

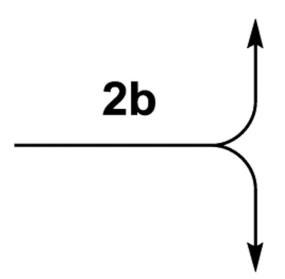

H-RullLn, dehydro-2b

Key optimization experiments for the enantioselective ruthenium C-C catalyzed coupling of 1,3-enyne 1a with benzylic alcohol $\mathbf{2 b . a}$

aYields are of material isolated by silica gel chromatography. Enantiomeric excess was determined by chiral stationary phase HPLC analysis. See Supporting Information for 
Nguyen et al.

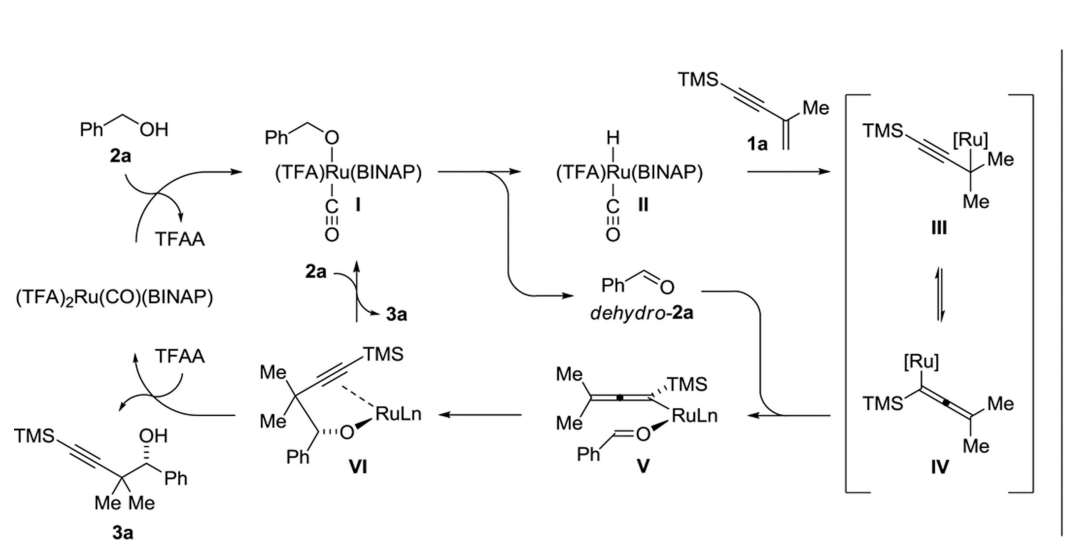

Page 9

Favored Mode of Addition

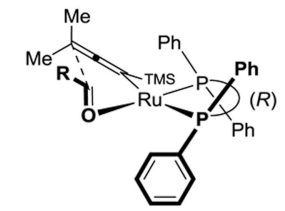

Apical Ligands Omitted for Clarity

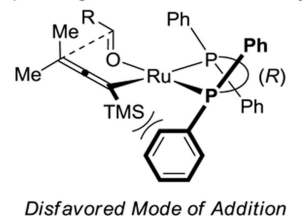

TMS<smiles>CC#CC(CC)(CC)C(O)([18OH])[18OH]</smiles>

Experiment I: $67 \%$ Yield deuterio-3b

Experiment II: $60 \%$ Yield deuterio-3b $d_{8}-2-\mathrm{PrOH}(300 \mathrm{~mol} \%)$

Experiment I Experiment II

$\mathrm{H}_{\mathrm{a}, \mathrm{b}}\left(70 \%{ }^{2} \mathrm{H}\right) \quad \mathrm{H}_{\mathrm{a}, \mathrm{b}}\left(130 \%{ }^{2} \mathrm{H}\right)$

$\mathrm{H}_{\mathrm{c}}\left(87 \%{ }^{2} \mathrm{H}\right) \quad \mathrm{H}_{\mathrm{c}}\left(53 \%{ }^{2} \mathrm{H}\right)$

$\mathrm{OH}$

$\overbrace{\mathrm{Br}}^{\mathrm{OH}}$

deuterio-2b

(100 mol\%)

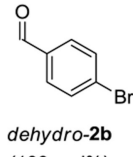

Scheme 2.

General catalytic mechanism, stereochemical model and deuterium labeling studies. 


\section{Table 1}

Enantioselective ruthenium catalyzed C-C coupling of 1,3-enyne 1a with alcohols $\mathbf{2 a - 2} \mathbf{r}$ to form homopropargyl neopentyl alcohols 3a-3r. ${ }^{a}$

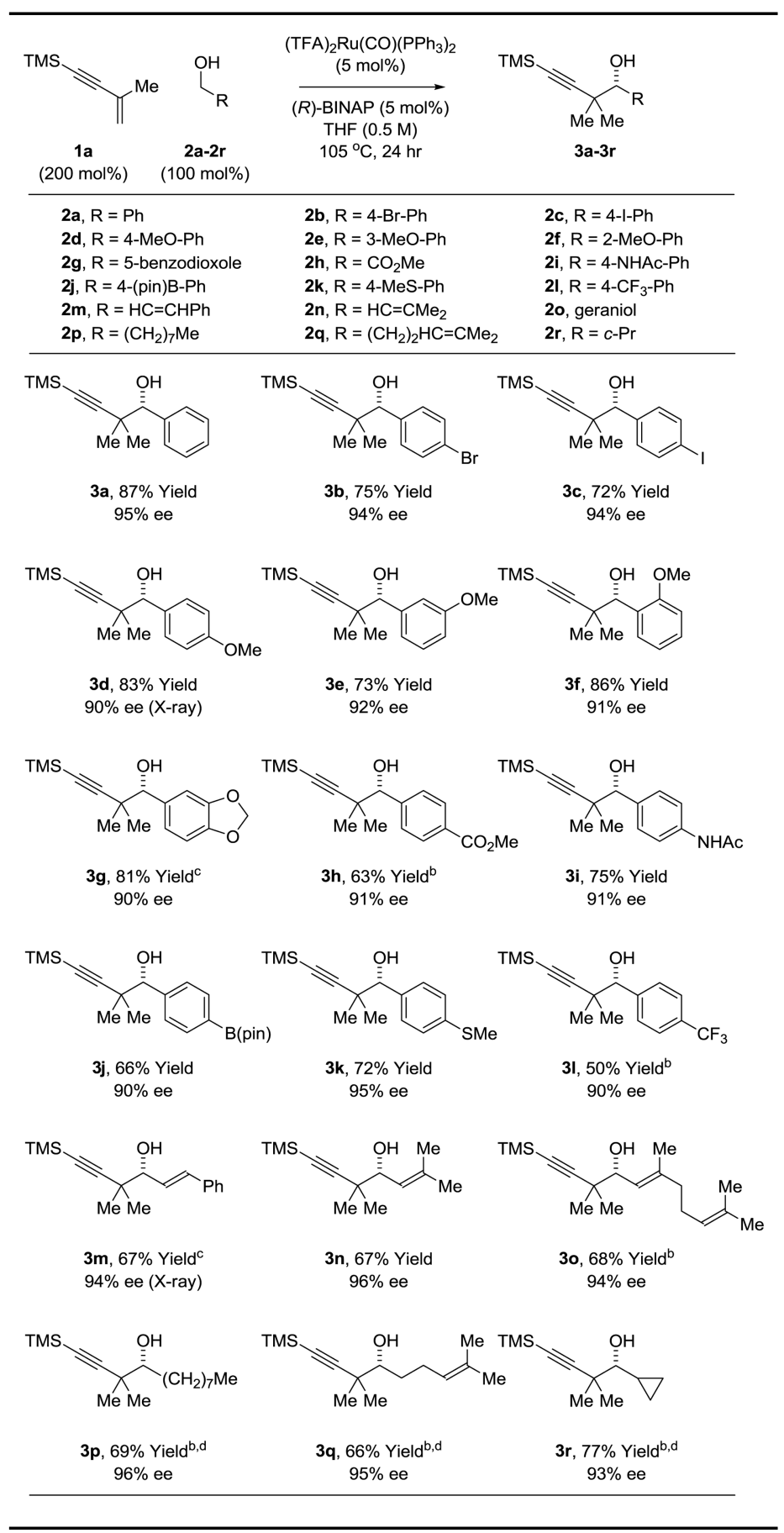

${ }^{a}$ Yields of material isolated by silica gel chromatography. See Supporting Information for further experimental details.

$b_{120}^{\circ} \mathrm{C}$. 
$c^{c} 5^{\circ} \mathrm{C}$.

$d_{48} \mathrm{hr}$.

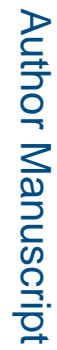

로을

를

로을

J Am Chem Soc. Author manuscript; available in PMC 2017 April 27. 